JRPIPM. Vol. 2 (2018, no. 1 15-22)

Jurnal Riset Pendidikan dan Inovasi Pembelajaran Matematika

ISSN: 2581-0480 (electronic)

URL: journal.unesa.ac.id/index.php/jrpipm

\title{
Analysis of Primary Students' Spatial Literacy on Reasoning
}

\author{
Elok Kartika Sari ${ }^{1}$ Rooselyna Ekawati ${ }^{2}$ \\ ${ }^{1}$ Universitas Negeri Surabaya, eloksari@mhs.unesa.ac.id \\ ${ }^{1}$ Universitas Negeri Surabaya, rooselynaekawati@unesa.ac.id
}

\begin{abstract}
Spatial thinking is critical to mathematical thinking and achievement, important not only in mathematics learning and but also important in education research. In order to have similar opportunity in supporting primary students' spatial literacy on reasoning, it needs a clearer picture of primary students' spatial literacy on reasoning in solving Mathematical Literacy Tasks (MLT) as the aim of this study. The characteristic of MLT satisfies the PISA framework and considering Context, Content (shape and space), Process as well as level of problem. Researcher only focuses on three MLT problems. The result is about description of analyzing three participants' solution of MLT based on how they use kinds of spatial literacy on reasoning strategies. Dimensional reasoning is effective but the students didn't use it often, the students seem like unfamiliar with these strategies. The responses suggest that because of the teacher didn't use dimensional strategies in the class, so the student commonly didn't use it often. Therefore, students need experiences that supporting their reasoning of spatial objects and its relationship and teacher can help students by using learning models, methods, or strategies in the class so their mathematical literacy (spatial literacy on reasoning) better than before.
\end{abstract}

Keyword: Spatial Literacy, Reasoning, Spatial, Reasoning, Primary Students

\section{Introduction}

Spatial literacy support our understanding of the (three dimensional) world in which we live and move [1]. Armstrong (2008) said that spatial literacy involves sensitivity to the colors, lines, shapes, spaces, and relationships that exist between them [2]. de Lange (2005) described spatial literacy as a person perception and understanding of spatial objects and relationships. There are three main domains in spatial literacy which are visualization, reasoning, and communication. Reasoning is process of organizing, comparing, or analyzing spatial concepts and its relationships ( [3]; [4]). Spatial thinking, or reasoning, involves the location and movement of objects and ourselves, either mentally or physically, in space. It is not a single ability or process but actually refers to a considerable number of concepts, tools and processes [5]. In Addition, spatial thinking involves three components: "concepts of space, tools of representation, and processes of reasoning" [5].

One of fundamental subject in mathematics that studied about it is geometry. Geometry is a specific branch of mathematics where one often makes use of spatial literacy skills while studying axioms, properties, and theorems related to points, curves, 
surfaces, and solids [4]. In North America, research has shown that geometry receives the least amount of time compared with other strands in classroom instruction ( [6]; [7]; [8]). Spatial reasoning allows mathematics to become a more visual representation and connects mathematics with real life (pattern) in the world. So, by exploring spatial things of mathematics, there is a relationship between spatial reasoning and mathematics learning itself.

"Research on spatial reasoning substantiates the critical importance of spatial reasoning abilities in geometry, measurement and problem solving both early in students' mathematics experiences as well as later in high school and beyond, especially in STEM (Sciences, Technology, Engineering and Mathematics) areas." ( [9]; [8]). In its report Learning to Think Spatially, the National Research Council [5] issued a call for action in education: that we recognize spatial thinking as important not only across mathematical strands but also across subject areas, and that educational researchers and system leaders develop better understandings and supports to foster spatial literacy in students [8]. So, we can conclude that spatial thinking is critical to mathematical thinking and achievement, important not only in mathematics learning and but also important in education research.

Nearly a century of research confirms the close connection between spatial thinking and mathematics performance ( $[10]$; [8]). A recent research by Moore-Russo, et. al said that seventy-five pre-service and in-service teachers worked on problems that involved spatial objects, their properties, and their relationships [4]. Teachers' responses suggested that their spatial literacy skills were underdeveloped with deficiencies most evident on problems that were solvable by dimensional reasoning. Poor vocabulary and misconceptions hindered teachers' performance. Teachers who used multiple reasoning strategies were more likely to solve a problem correctly. But, in the recent research titled Description Ability of Literacy Mathematics Student of SMP Negeri In District of North Buton by Qasim, et. al. [11], pursuant to result of data analysis of TKLM (Test Ability Of Literacy Mathematics) obtained that the mean ability of student mathematics literacy of SMP Negeri in Distric of North Buton still low, that is less than 60\% to each level. In scale 100 , the mean ability of student mathematics literacy only equal to 5,9 . In order to have similar opportunity in supporting primary students' spatial literacy, it needs a clearer picture of primary students' spatial literacy on reasoning. Based on explanation above, researcher interested about Analysis of Primary Students' Spatial Literacy on Reasoning. This study aimed at analyzing sixth grade primary students' spatial literacy on reasoning in solving Mathematical Literacy Tasks (MLT).

\section{Methods}

This paper focuses about sixth grade primary students' spatial literacy on reasoning. We consider primary students' responses to items in two- and three-dimensional environment.

\subsection{Participants}

From 54 sixth grade primary students in Surabaya who asked to solve Mathematics Literacy Tasks (MLT), researcher chose three participants who have high score to analyze their spatial literacy on reasoning.

\subsection{Instruments and data collection}


The remaining data were collected using paper and pencil test (instrument) called Mathematics Literacy Tasks (MLT). The characteristic of MLT satisfies the PISA framework and considering Context, Content, Process as well as level of problem. MLT consist of 5 problems about shape and space. But researcher only focus on three essay problems in two- and three-dimensional environment which is in number 7, 9, and 11 . Table 1 showed the description of MLT based on context, content, process, level, and description.

Table 1 Showed The Description Of MLT

\begin{tabular}{llllll}
\hline No & Context & Content & Process & Level & Description \\
\hline 7 & Social & $\begin{array}{l}\text { Space and } \\
\text { shape }\end{array}$ & Interpret & 4 & $\begin{array}{l}\text { Interpreting visual form of object with } \\
\text { given its volume }\end{array}$ \\
\hline 9 & Personal & $\begin{array}{l}\text { Space and } \\
\text { shape }\end{array}$ & Formulate & 5 & $\begin{array}{l}\text { Formulate a simple mathematics model } \\
\text { that related to concept of pattern }\end{array}$ \\
\hline 11 & Personal & $\begin{array}{l}\text { Space and } \\
\text { shape }\end{array}$ & Interpret & 4 & $\begin{array}{l}\text { Drawing cubes' net based on the cube's } \\
\text { side }\end{array}$ \\
\hline
\end{tabular}

To describe the students' spatial literacy on reasoning, the researcher gave the tests as follows:

.7. Rice Box's Order

A consuming committee of seminar event forgot to count the total of rice box when she put it on the table. But she can calculate it by observing the pattern of rice box arrangement on the table as shown in the following figure.

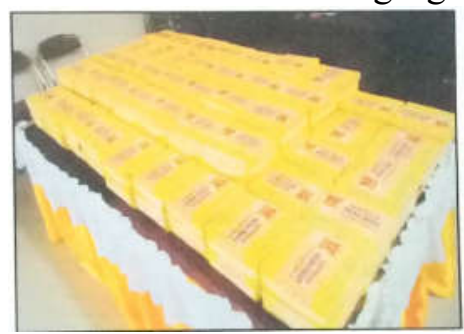

Figure 1 Illustration for rice boxes

Calculate the total of rice box on the table. Explain your strategy.

\section{.9. A Ceremony}

In a ceremony, Joko standing in the back row was called by his teacher to report the number of students in his group. The teacher will give cake for the students who participate the ceremony. Joko didn't know exactly the number of students in his group, but he realized that there were 4 students in his left side, 2 students in his right side, 5 students in front of him, and one student in the front as lead of the group. How many students that must be reported to the teacher? Explain your answer!

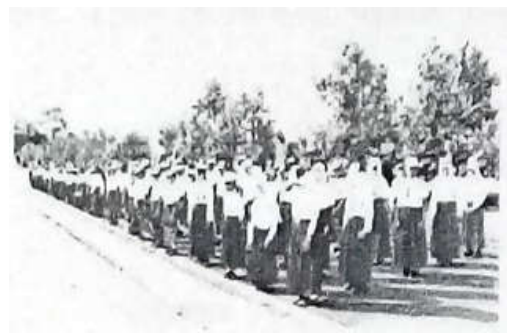

Figure 2 Illustration for students flag ceremony 
11. Make Nets of a Box

The net of a box can be made by opening the edges of the box. Arrow in the picture below showed the direction of cutting the edge of a box.

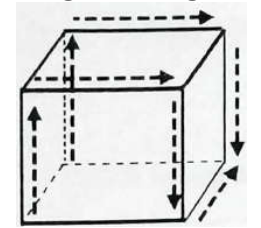

Figure 3 Illustration for the cutting direction on the box

Draw the net of the box based on the picture above!

\subsection{Data analysis}

The test was given to all the students (54 students). After getting the results, it sorted from high to low values. Researcher chose three participants who have high score coded as P1 for participant 1, P2 for participant 2, and P3 for participant 3. From three participants, researcher analyzed their answer based on their spatial literacy on reasoning strategies [4], which have indicators that coded as.

1. Use of drawing (D)

2. Use of example (E)

3. Use of algebraic reasoning (AR)

4. Use of dimensional reasoning (DR)

5. Incorrectly forcing three-dimensional into two-dimensional situations (IF)

During analyze three participants' work for these five reasoning variables, many responses were found to contain mathematical misconceptions.

\section{Results}

The first participant (P1) spatial literacy on reasoning showed in the Figure 1 below.

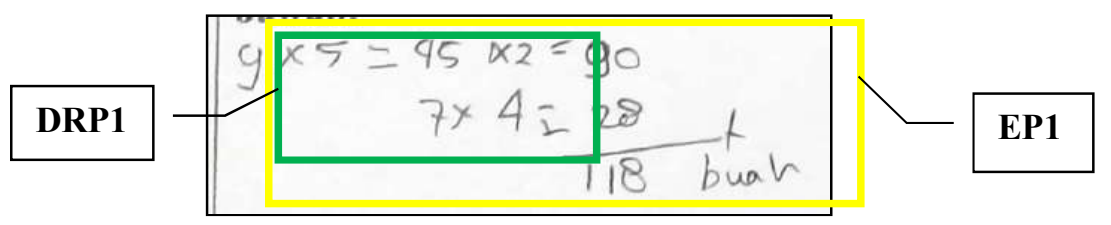

(a)

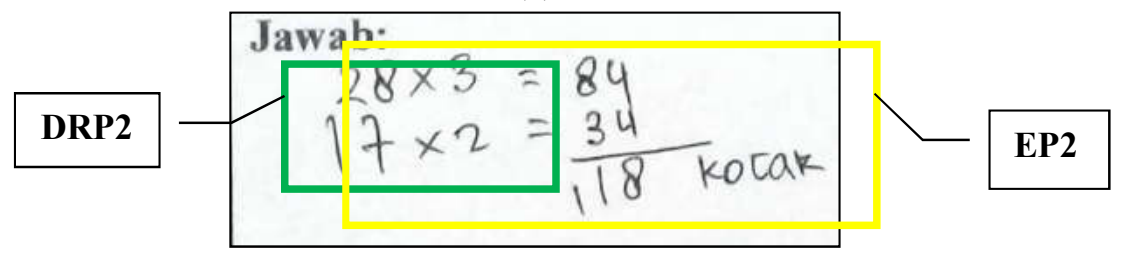

(b)

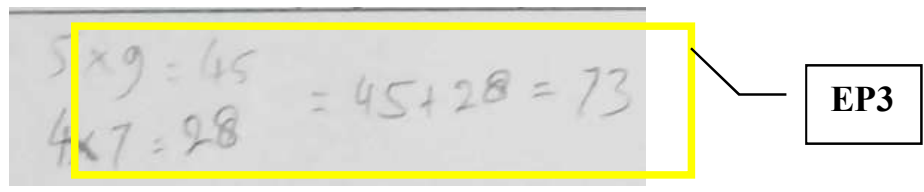

(c)

Figure 4. (a) MLT number 7 answer of P1, (b) P2, and (c) P3. 
In the Figure 1, we can see that all of the students solve the problem by using examples (EP1, EP2, and EP3) based on the picture in the problem. Students have to solve the problem about interpreting visual form of object with given its volume. $70 \%$ of students could answer the problem in number 7 correctly. DRP1 showed that P1 determine the total of rice box by calculate the volume of cuboid $(9 \times 5=45 \times 2=90)$ and $(7 \times 4 \times 1=28)$. DRP2 showed that $\mathrm{P} 2$ determine the total of rice box by calculating the volume of cuboid $(7 \times 4=28 \times 3=84)$ and other volume but it is not cube or cuboid $(17 \times 2 \times 1=28)$. From Figure 1(a), (b), and (c) showed that no one use algebraic reasoning to solve it even though this problem is possible to solved by using algebraic reasoning.

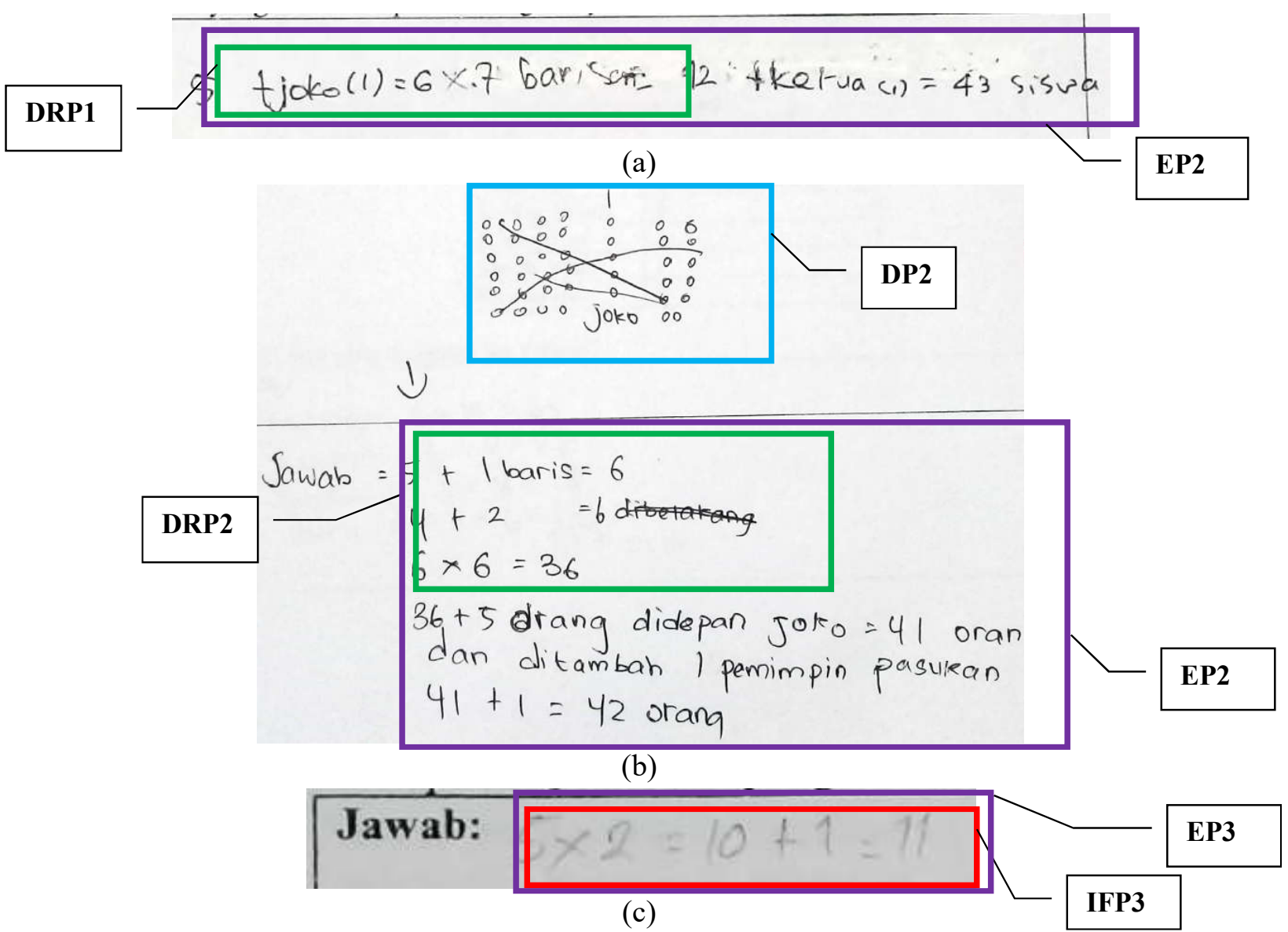

Figure 5. (a) MLT number 9 answer of P1, (b) P2, and (c) P3.

Figure 2 showed the answer of $\mathrm{P} 1, \mathrm{P} 2$, and $\mathrm{P} 3$ in number 9 to formulate a simple mathematics model that related to concept of pattern. There was only $9 \%$ students could answer the problem in number 9 . Use of drawing only used by participant 2 showed in DP2. Use of examples (EP1, EP2, and EP3) was used by all the participants but P2 and P3 still difficulties. Use of dimensional reasoning (DRP1, DRP2) showed in Figure 2(a) and 2(b) but P3 only calculate what is given in the text without using their dimensional reasoning. Figure 2(c) showed that P3 still has difficulty or incorrectly forcing threedimensional objects into two-dimensional objects (IFP3) so the answer is wrong. 


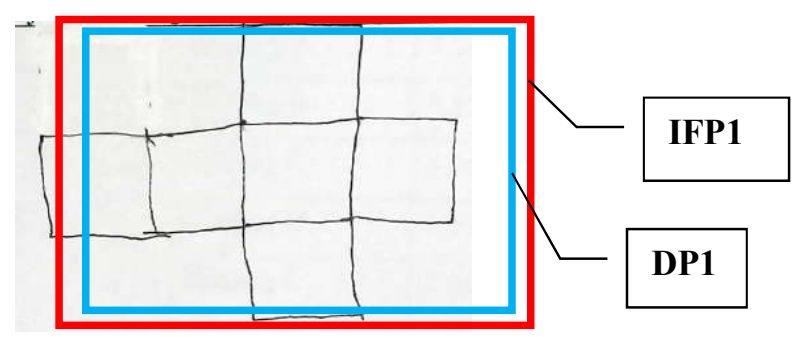

(a)

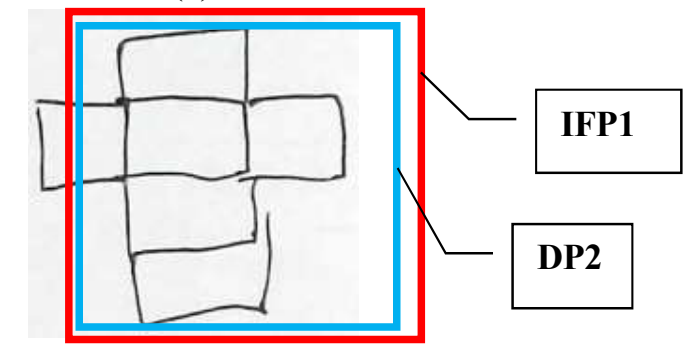

(b)

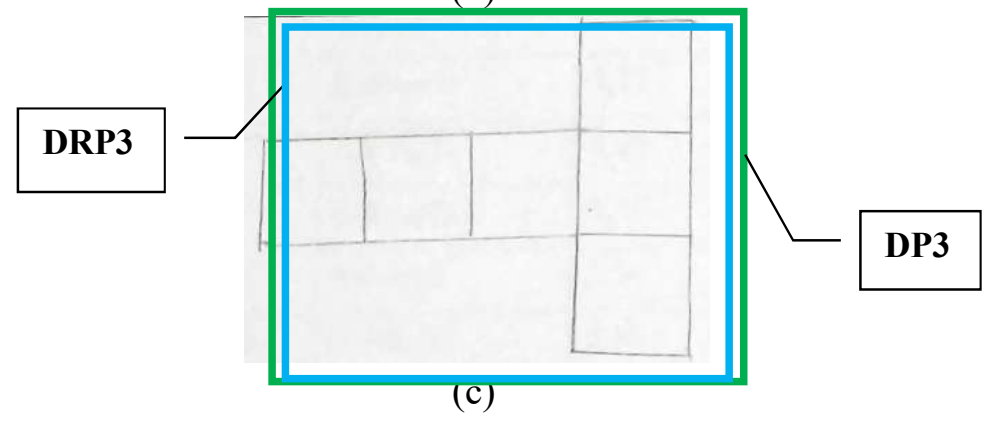

Figure 6. (a) MLT number 11 answer of P1, (b) P2, and (c) P3.

There were only $2 \%$ students could answer the problem in number 11 that showed in Figure 3 above. All of the participants solve the problem by drawing (DP1, DP2, and DP3) based on the picture in the problem. It found that two from three participants have difficulty in drawing the net of cube by following the cutting direction. It can be considered from Figure 3(a) and 3(b) that students still have difficulty or incorrectly forcing three-dimensional objects into two-dimensional objects (IFP1, IFP2) even though they are the students with high mathematical literacy. The use of dimensional reasoning showed in DRP3 when P3 can imagine and change three-dimensional figures into twodimensional figures.

\section{Conclusion}

This study used spatial literacy on reasoning to analyze sixth grade primary student's solutions in solving MLT problems. The characteristic of MLT satisfies the PISA framework and considering Context, Content, Process as well as level of problem. MLT consist of 5 problems about shape and space. But researcher only analyzes three problems which are number 7, 9, and 11. By considering it, we explored some aspects of spatial literacy on reasoning in order to understand how students' performance in solving tasks about spatial objects and its relationship. 
The research question focused on the reasoning domain of spatial literacy by considering students' reasoning strategies to solve the problems. The students used some kinds of strategies in their solution to each problem. Based on the result of analysis data and the description above, $70 \%$ of students could answer the problem in number 7 correctly. In solving MLT number 7 about interpreting visual form of object with given its volume. There was only $0.09 \%$ students could answer the problem in number 9 which is about to formulate a simple mathematics model that related to concept of pattern. There was only $0.02 \%$ students could answer the problem in number 11 . All of participants using examples in solving number 7 and 9 but participant 3 had wrong calculation on it and didn't use dimensional reasoning to solve it too. Each of participants used different dimensional reasoning. They didn't use algebraic reasoning to solve problem 1 even though this problem is possible to be solved by using algebraic reasoning. Use of drawing only used by participant 2 showed in DP2. It found that two from three participants have difficulty in drawing the net of cube by following the cutting direction. It can be considered that they incorrectly forcing three-dimensional objects into two-dimensional objects even though they are the students with high mathematical literacy.

Each of the five strategies employed had a positive overall effect on their spatial literacy scores, the single most effective reasoning strategy was the use of dimensional reasoning [4]. As the results showed that dimensional reasoning is effective but the students didn't use it often, the students seem like unfamiliar with these strategies. Because in the past research showed that if a teacher is not aware with a strategy, his or her students didn't experience that strategy in their classroom ( [12]; [13]; [4]). The responses suggest that because of the teacher didn't use dimensional strategies in the class, the student commonly didn't use it often. So, the student will only use their knowing strategies to solve a problem. Therefore, we conclude that students need experiences that supporting their reasoning of spatial objects and its relationship. Hence, teacher can improve their students on it by using learning models, methods, or strategies in the class so their mathematical literacy (spatial literacy on reasoning) better than before.

\section{References}

[1] J. de Lange, "Literacy, Mathematical," Encyclopedia of Social Measurement Vol. 2, pp. 533-540, 2005.

[2] M. Elisa, "Deskripsi Kemampuan Spasial Ditinjau dari Gaya Belajar Siswa Kelas VII SMP Negeri 8 Purwokerto pada Materi Geometri," Universitas Muhammadiyah Purwokerto, Purwokerto, 2016.

[3] M. Battista, The Development of Geometric And Spatial Thinking. In F.K. Lester, Jr. (Ed.), Second handbook of research on mathematics teaching and learning (pp. 843-908), Charlotte, NC: National Council of Teacher of Mathematics/ Information Age Publishing, 2007.

[4] D. Mooree-Russo, J. M. Viglietti, M. M. Chiu and S. M. Bateman, "Teachers' Spatial Literacy as Visualization, Reasoning, and Communication," Teaching and Teacher Education 29, pp. 97-109, 2013.

[5] N. National Research Council, Learning to Think Spatially, Washingto, D.C.: The National Academic Press, 2006. 
[6] Bruce, C., Moss, J., \& Ross, J., "Survey of JK to Grade 2 teachers in Ontario, Canada: Report to the Literacy and Numeracy Secretariat of the Ministry of Education.," Ontario Ministry of Education, Toronto, ON, 2012.

[7] Clements, D.H., \& Sarama, J. , "Early Childhood Teacher Education: THe Case of Geometry," Journal of Mathematics Teacher Education, pp. 133-148, 2011.

[8] ONTARIO, Paying Attention to Spatial Reasoning Support: Document for Paying Attention to Mathematics Education, USA: ONTARIO, 2014.

[9] J. Shumway, "Building bridges to spatial reasoning," Teaching Children Mathematics, 20(1), pp. 44-51, 2013.

[10] Mix, K.S., \& Cheng, Y.-L., "The relation between space and math: Developmental and educational implications.," in Advances in child development and behavior, San Diego, CA, Academic Press, 2012, pp. 197-243.

[11] Qasim. Kadir, Awaluddin, "Deskripsi Kemampuan Literasi Matematika Siswa SMP Negeri Di Kabupaten Buton Utara," Jurnal Penelitian Pendidikan Matematika , 2015.

[12] Webb, N.W., \& Farivar, S., "Developing productive group interaction in middle school mathematics," in Cognitive prespectives on peer learning, Mahwah, NJ, Erlbaum, 1999, pp. 117-149.

[13] Webb, N.W., Nemer, K. M., \& Ing, M. , "Small-group reflections: parallels between teacher discourse and student behavior in peer-directed groups," Journal of the Learning Sciences, pp. 63-119, 2006.

[14] K. Schwartz, "Why Spatial Reasoning Is Crucial For Early Math Education," -, -, 2017.

[15] Wright, R., Thompson, W. L., Ganis, G., Newcomber, N.S., L\& Kosslyn, S.M., "Training generalized spatial skills," Psychonomic Bulletin \& Rewiew, pp. 763-771, 2008. 